\title{
THE EFFECT OF ALTERATIONS IN BLOOD VOLUME ON THE ANEMIA AND HYPOPROTEINEMIA OF HUMAN MALARIA ${ }^{1}$
}

\author{
By HARRY A. FELDMAN ${ }^{2}$ AND FRANKLIN D. MURPHY ${ }^{3}$ \\ (From the Division of Preventive Medicine, University of Tennessee, Memphis)
}

(Received for publication May 31, 1945)

There is general agreement that humans with active malarial infections ${ }^{4}$ develop amenia and hyproproteinemia. The anemia is usually considered to be secondary to erythrocyte destruction by the intracellular parasites, but no adequate explanation has been offered for the hypoproteinemia. Since laboratory techniques commonly used measure only the relative amounts of chemical and cellular components of the blood, it cannot be assumed that these relative measurements always reflect fluctuations in the total amounts of these constituents.

In order to determine alterations in the total amounts of circulating plasma proteins and red blood cells, this study of the blood volume changes associated with clinically active, untreated malaria was undertaken. Simultaneous determinations of the plasma proteins, plasma bilirubin, and erythrocyte concentrations were made so that the relative and total amounts of these elements might be calculated and compared.

\section{METHODS AND MATERIALS}

Nine patients with central nervous system syphilis, but otherwise relatively normal, served as experimental subjects. The group consisted of 5 white and 3 negro males and 1 negro female. Four patients were inoculated by the bites of Anopheles quadrimaculatus infected with Plasmodium vivax (McCoy strain), 1 patient by the intravenous administration of trophozoites of $P$. vivax ( $\mathrm{McCoy}$ strain), and 4 patients by the intravenous injection of trophozoites of $P$. falciparum (Costa strain). These data are summarized in Table I.

1 The work described in this paper was done under a contract, recommended by the Committee on Medical Research, between the Office of Scientific Research and Development and the University of Tennessee.

2 Major, MC, AUS.

s Captain, MC, AUS.

4 For the purpose of this report, the period of active malaria is considered to be the period of visible parasitemia. Consequently, the days of disease are the days of parasitemia, while days which precede or follow the days of parasitemia are identified by minus or plus signs respectively.
Parasite counts were performed daily on the peripheral blood (1).

Plasma volume was measured (in fasting subjects) with the dye T-1824 (2). However, it was suggested (3) that a single 10-minute sample of blood be used in place of an extrapolation curve to calculate the degree of dye dilution and this was done, except that we employed a single 15-minute sample. Patients were given $5 \mathrm{ml}$. of a 0.5 per cent solution of the dye 5 for each measurement and the absorption coefficient of the dyed plasma was then determined with a Beckman photoelectric spectrophotometer.

TABLE I

Summary of descriptive data concerning 9 malaria patients studied by the T-1824 blood volume method

\begin{tabular}{c|c|c|c|c|c}
\hline \hline Patient & Sex & Color & Age & \multicolumn{1}{|c|}{ Species } & Method of inoculation \\
\hline 1 & M & W & 29 & P. vivax & Trophozoites \\
2 & M & C & 35 & P. falciparum & Trophozoites \\
3 & M & C & 43 & P. falciparum & Trophozoites \\
4 & M & W & 39 & P. vivax & Sporozoites \\
5 & M & W & 41 & P. vivax & Sporozoites \\
6 & M & W & 34 & P. vivax & Sporozoites \\
7 & F & C & 36 & P. falciparum & Trophozoites \\
8 & M & W & 48 & P. vivax & Sporozoites \\
9 & M & C & 43 & P. falciparum & Trophozoites \\
\hline
\end{tabular}

All blood samples were heparinized and, in addition to dye concentration, were analyzed for plasma protein concentration (4), for plasma bilirubin (5), and for red blood cell concentration by means of the hematocrit index. Hematocrits were done in duplicate and centrifuged for 30 minutes at 3,000 r.p.m. in Wintrobe tubes.

White patients who had plasma volumes determined on consecutive or nearly consecutive days became visibly discolored, and this served as a limiting factor for the frequency with which determinations could be made in the same individual. This "blueing" of the skin gradually disappeared over a period of from several days to a few weeks.

Each patient had one or more "base-line" plasma volume measurements during the period prior to the clinical expression of malaria. Further plasma volume determinations were made during both febrile and afebrile phases of clinical activity and, whenever possible, during convalescence.

5 Obtained from the William $R$. Warner Company of New York, N. Y., in ampoules of this size. 
BLOOD VOLUME ALTERATIONS IN HUMAN MALARIA

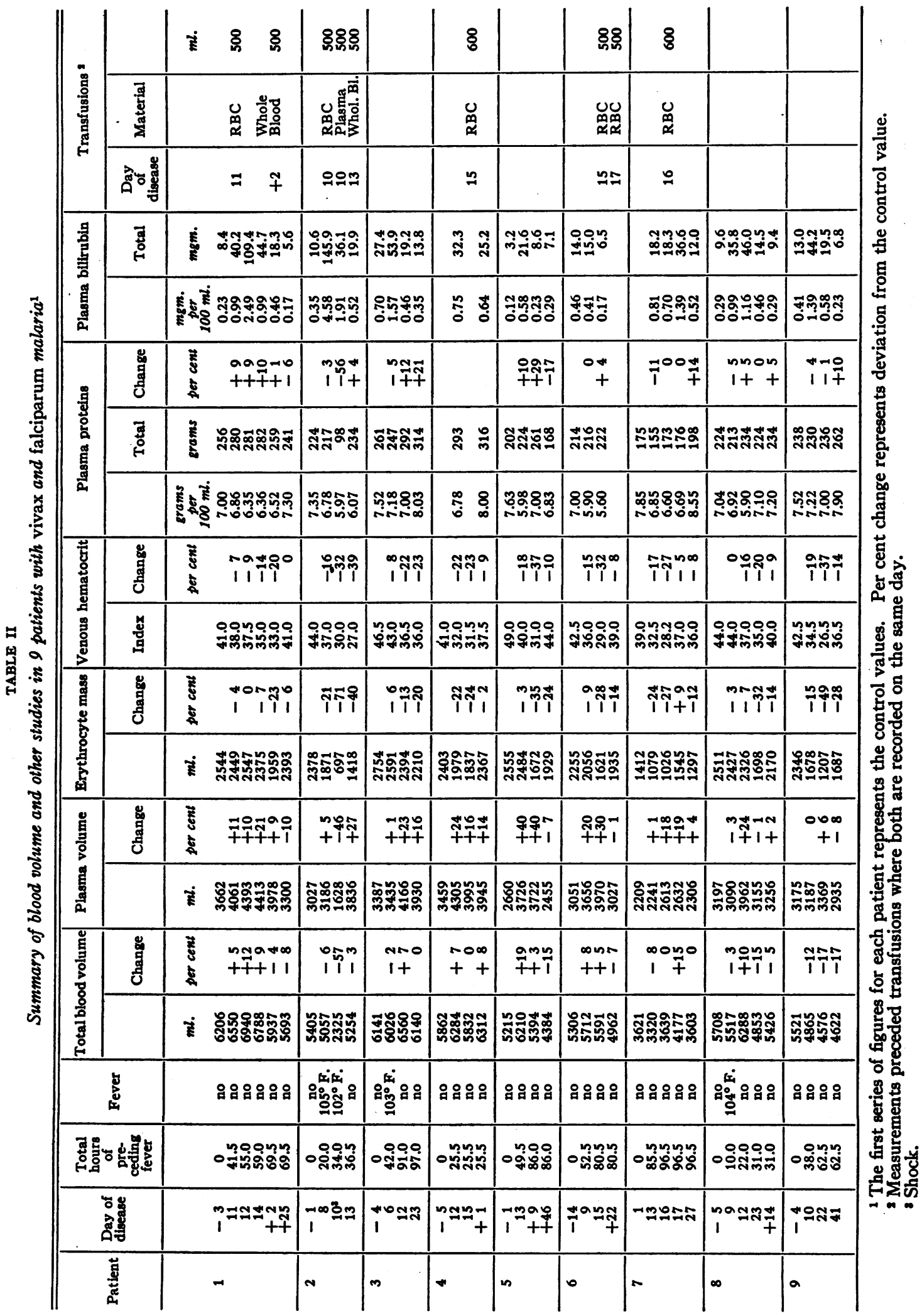




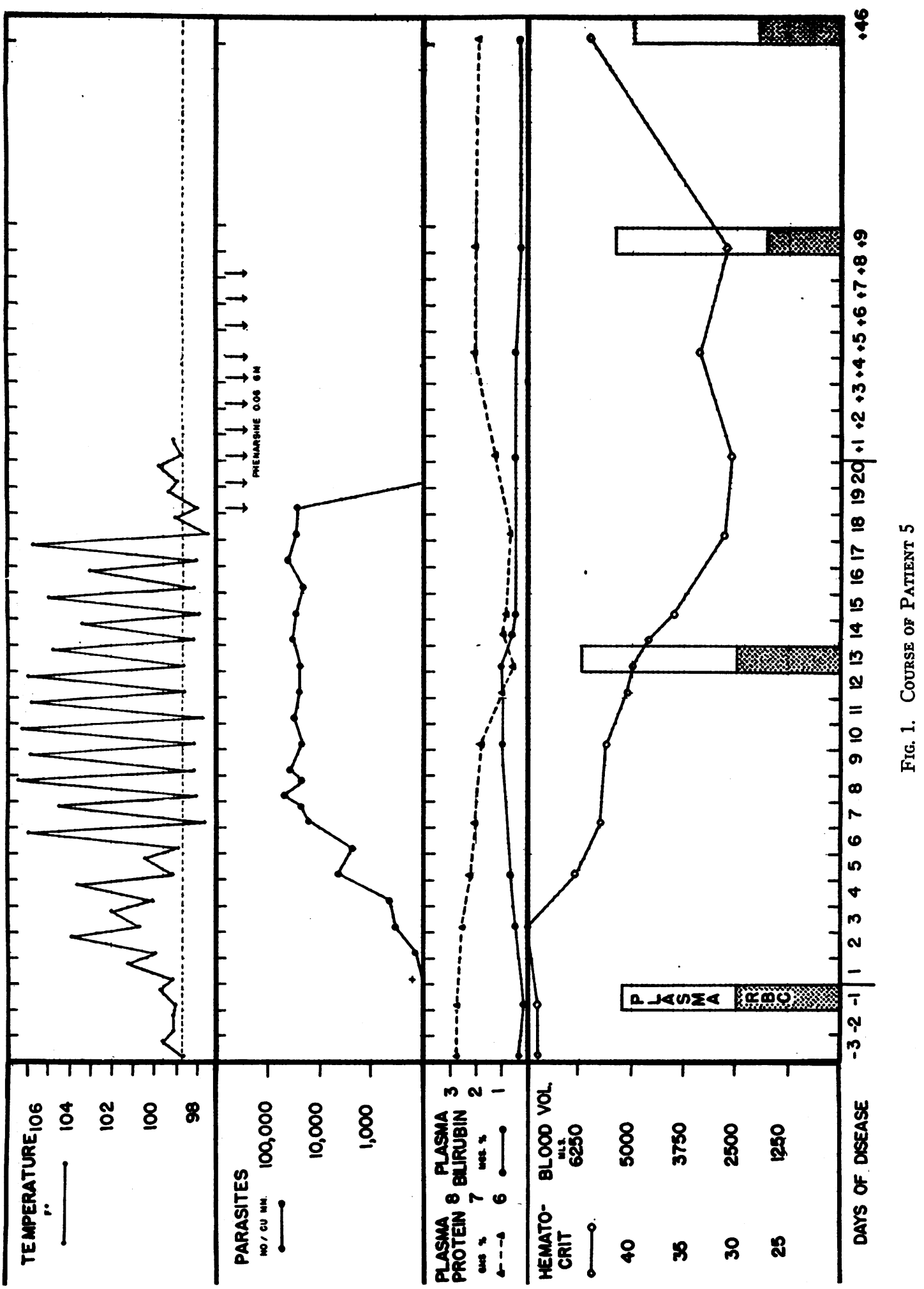




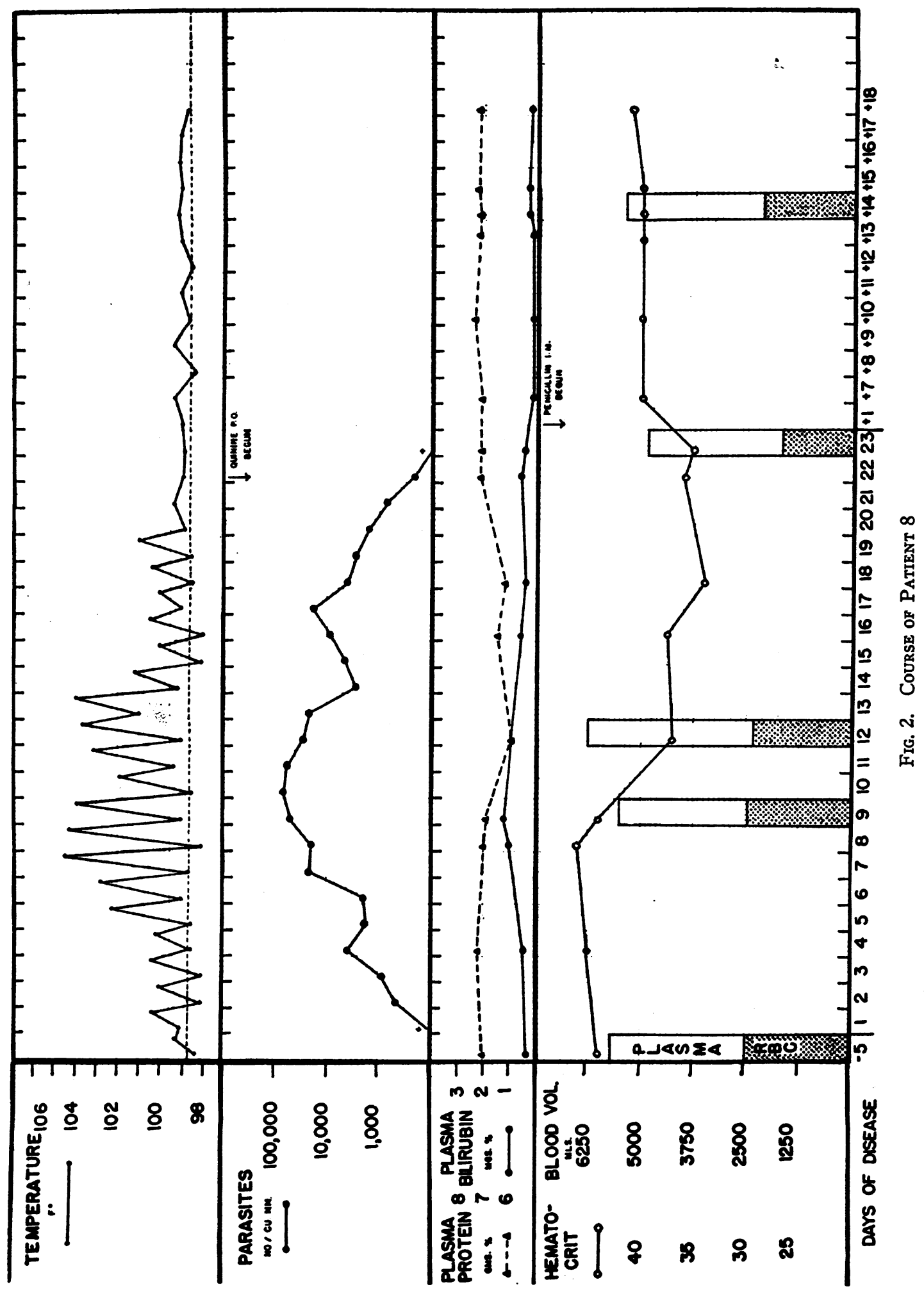




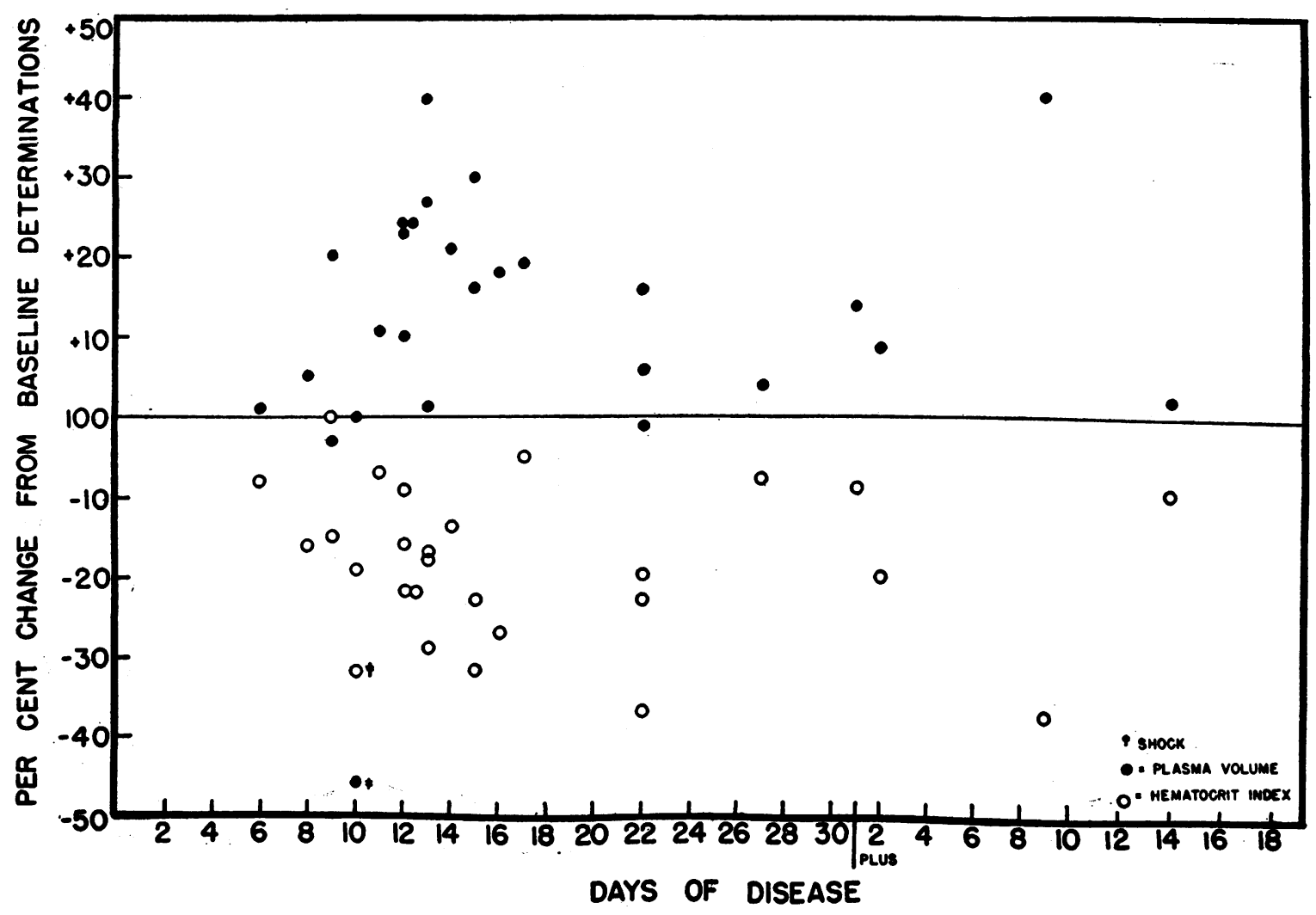

Fig. 3. Relation of Plasma Volume to Hematocrit Alterations

DATA AND DISCUSSION

\section{Plasma volume}

Erythrocyte destruction is a constant concomitant of all active malarial infections. Hence, it was expected, a priori, that the plasma volumes of the patients studied would be increased if a stable blood volume were to be maintained. The data summarized in Table II tend to support this concept, for the plasma volume is increased almost without exception during the active phase of the vivax and falciparum infections studied. However, the plasma volume increase may exceed the calculated loss in circulating erythrocytes, resulting in hemodilution with a lowering of the venous hematocrit out of proportion to the actual decrease in total erythrocyte mass (Figures 1 to 3 , and Table II, patients 5 and 8 ). This dilution phenomenon, which has also been observed in pneumococcal pneumonia (6), tends to occur shortly

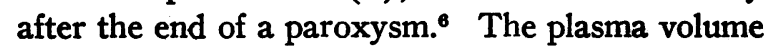
tends to be lower during the paroxysm than dur-

- The febrile excursion associated with schizogony, whether or not accompanied by a definite chill. ing the afebrile periods, probably the result of excessive loss of extracellular water by perspiration.

\section{Erythrocyte mass}

The mass of circulating erythrocytes was determined in all instances by subtracting the plasma volume from the calculated total blood volume. As would be anticipated in a disease in which there is continuing blood cell destruction, the erythrocyte mass progressively decreases with the course of the disease (Table II).

The validity of the value for erythrocyte mass obtained by the T-1824 method has been challenged by several workers $(7,8)$, who suggest that the calculated value is about 25 per cent higher than the actual value. However, since our experiments are concerned with alterations in total amounts rather than the total value per se, this error, if relatively constant, would appear to play a minor role in the interpretation of these data. The course of a patient who received $600 \mathrm{ml}$. of red blood cells immediately following a blood volume determination is illustrated in Figure 4. 


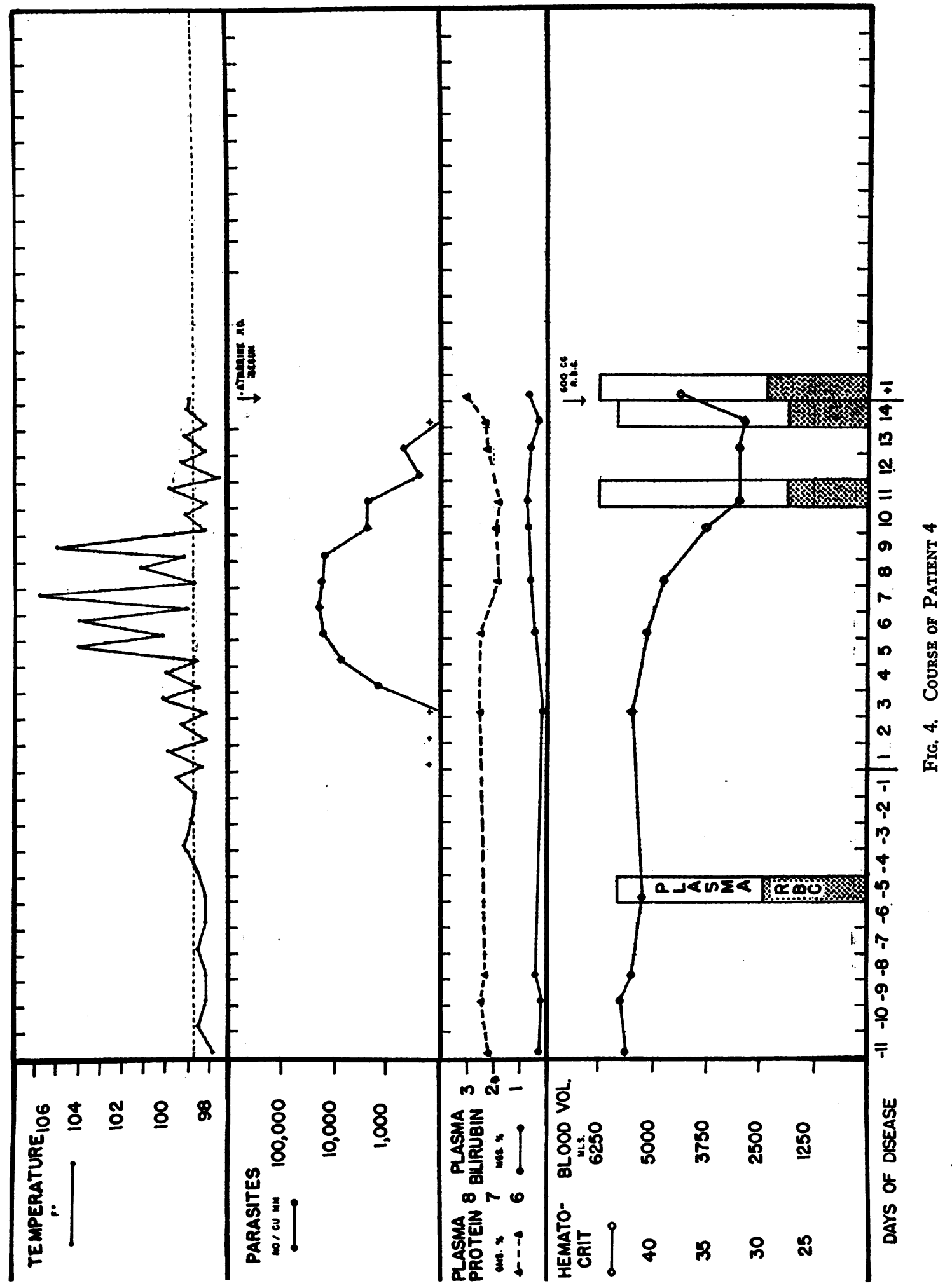




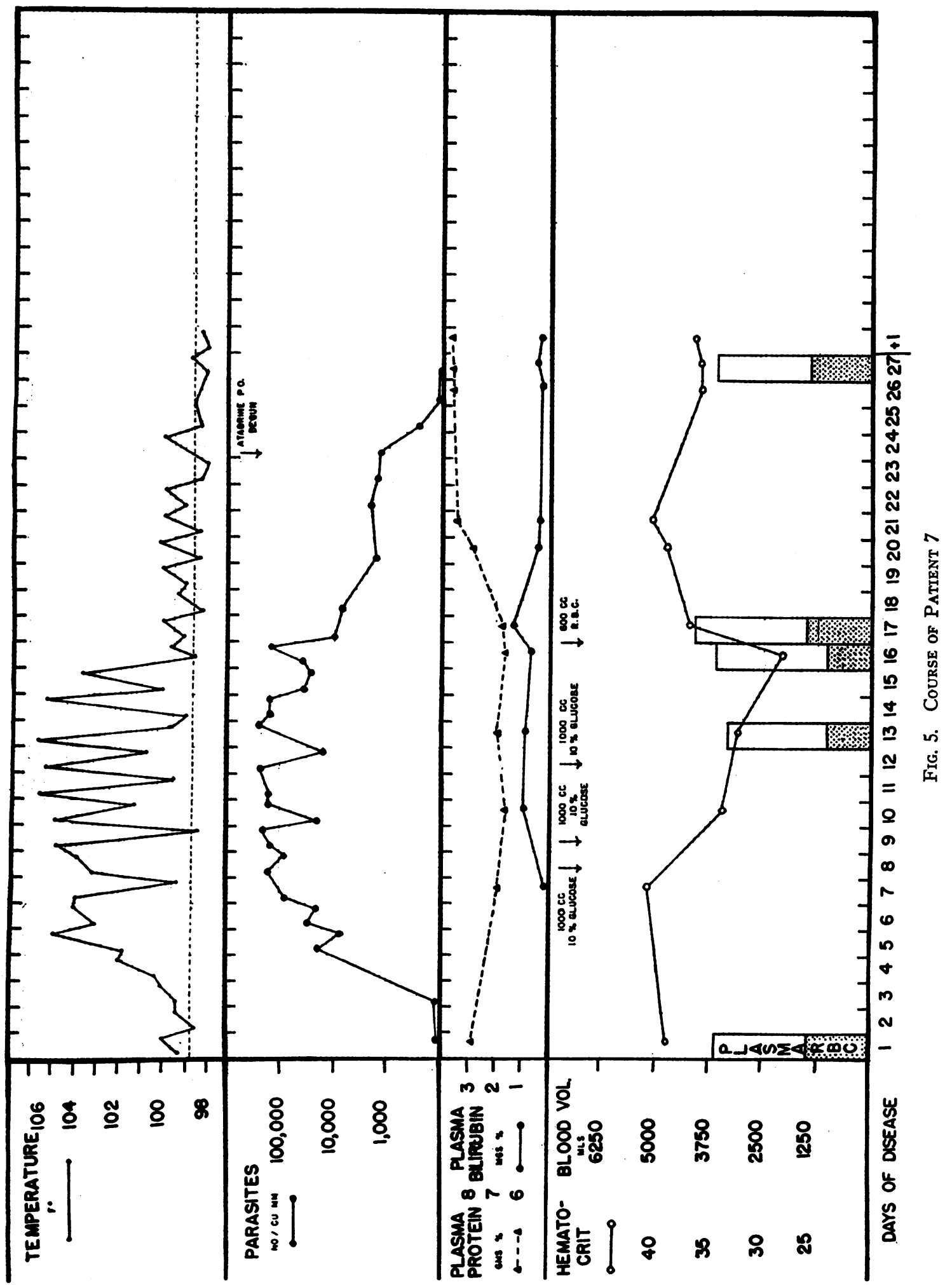




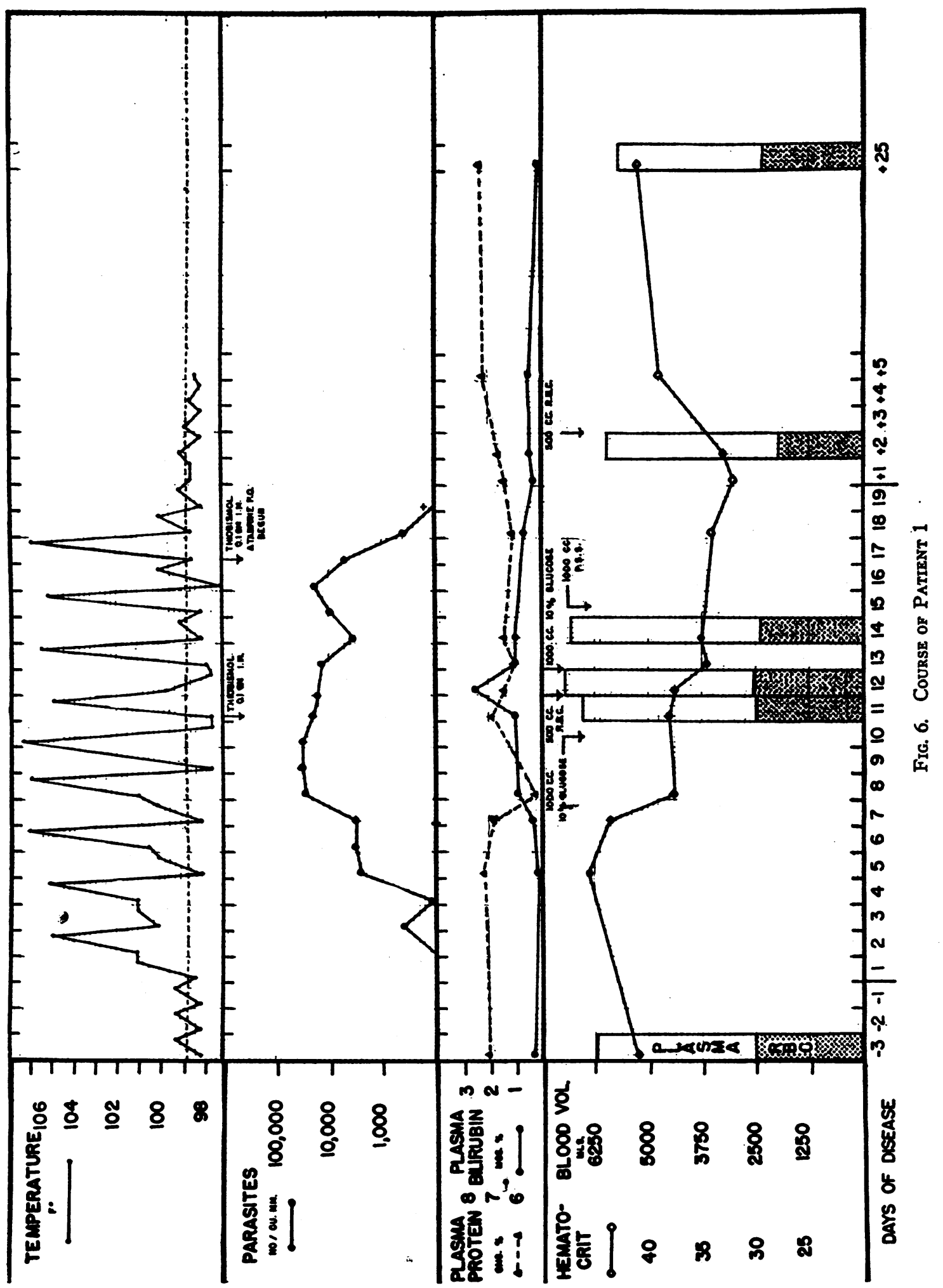


On the following day another blood volume determination revealed that the red cell mass had increased by $530 \mathrm{ml}$. and the plasma volume by $50 \mathrm{ml}$. Another such patient, in whom 519 of 600 $\mathrm{ml}$. of transfused erythrocytes were detected on the day following transfusion, is shown in Figure 5. Since the red blood cells were of necessity suspended in a small amount of plasma, the accuracy of the above determinations is probably greater than would appear. In 1 patient (Figure $6)$, however, the red cell mass increased only $98 \mathrm{ml}$. on the day following a transfusion of 500 $\mathrm{ml}$. of erythrocytes, while the plasma volume increased $330 \mathrm{ml}$. This could be explained by the occurrence of a hemolytic transfusion reaction as reflected by the sharp increase in plasma bilirubin from 0.99 to $2.45 \mathrm{mgm}$. per $100 \mathrm{ml}$.

\section{Total blood volume}

The total blood volume, calculated from the hematocrit and the value for plasma volume, tends to be slightly lower during fever and higher during the immediate post-paroxysm, afebrile phase. These fluctuations, usually not great, result mainly from changes in the plasma component of the blood. Observations on 4 patients during various stages of convalescence (Table II, patients 1,5 , 6 and 8 ) suggest that the total blood volume tends to be decreased in convalescence primarily because the plasma volume does not remain sufficiently increased to make up for the reduction in red cell mass. The lowered plasma volume may result in part from the significant loss of body weight which these patients incur during the course of the disease.

\section{Venous hematocrit index}

A progressive fall in the venous hematocrit index begins on the third or fourth day after the appearance of parasites and continues for several days after their disappearance. This hematocrit fall reflects the direction of change but does not indicate the quantitative alterations in erythrocyte mass (Figure 7). The latter inaccuracy results, in many instances, from hemodilution, so that, for example (Figure 2), a drop of 7 points in the hematocrit on day 12 is due almost entirely to this phenomenon. In general, it may be said that in human malaria of the character reported in this

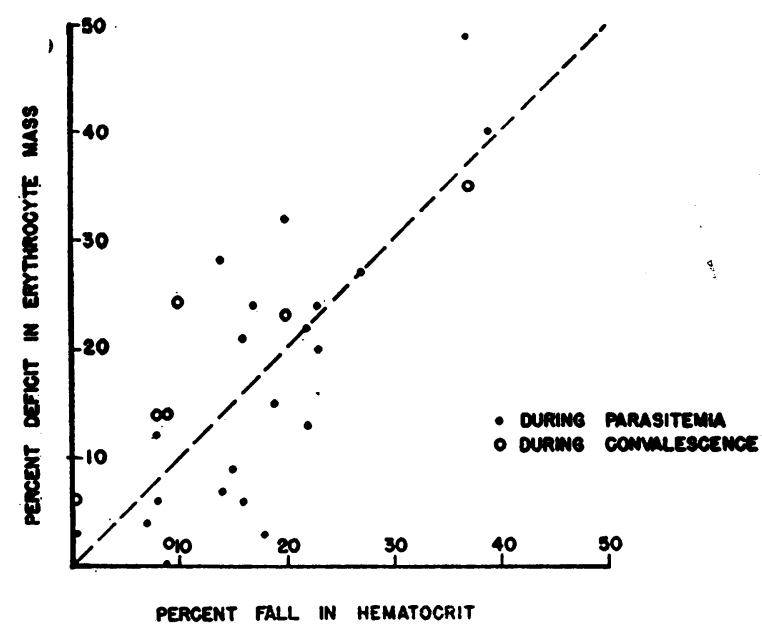

Fig. 7. Correlation between Deficit in Erythrocyte Mass and Hematocrit Fall

study a single hematocrit index gives only an approximation of the true state of anemia, although a series of such determinations will point the direction of erythrocyte change.

\section{Plasma bilirubin}

The plasma bilirubin increases shortly after parasites appear in the blood and returns to normal following the end of the parasitemia. This increase, which is magnified considerably by calculation of the total circulating bilirubin (Table II), appears to be a reflection of the destruction of erythrocytes (Figure 8). As will be noted, this evidence of destruction may reach considerable proportions.

\section{Anemia}

These studies infer that at least 2 factors are operating in the production of the normochromic, normocytic anemia of malaria; i.e., erythrocyte destruction and hemodilution. Bone marrow studies (9) suggest the possibility of a third factor; namely, maturation arrest of the erythrocyte series.

\section{Plasma proteins}

The decrease in the concentration of plasma proteins during malarial infections has been reported $(10,11)$ to be due principally to the reduction of the albumin fraction. While our basic data are in agreement with the belief that the relative concentration of plasma proteins falls, 


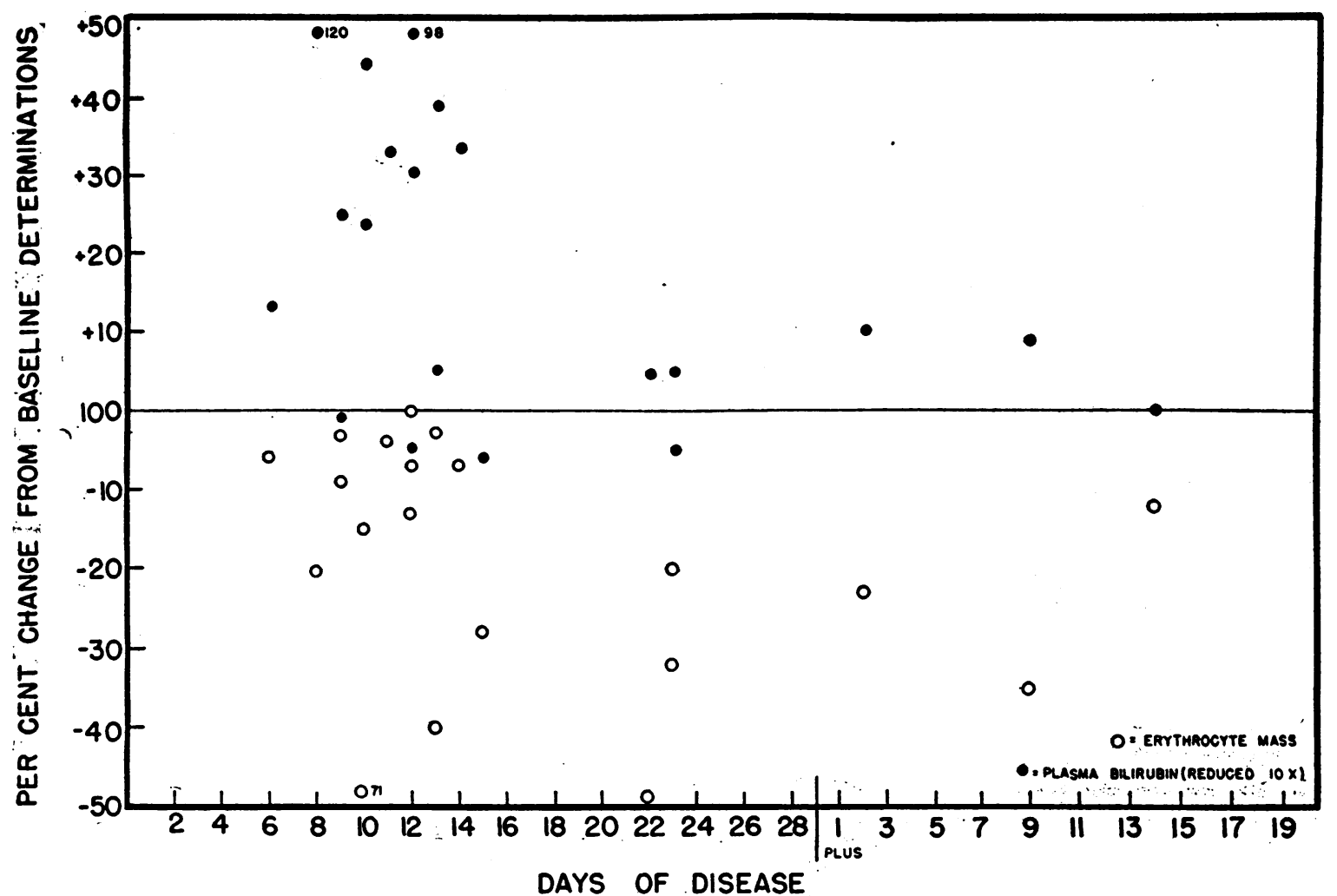

Fig. 8. Rejation of Plasma Bilirubin to Alteration in the Erythrocyte Mass

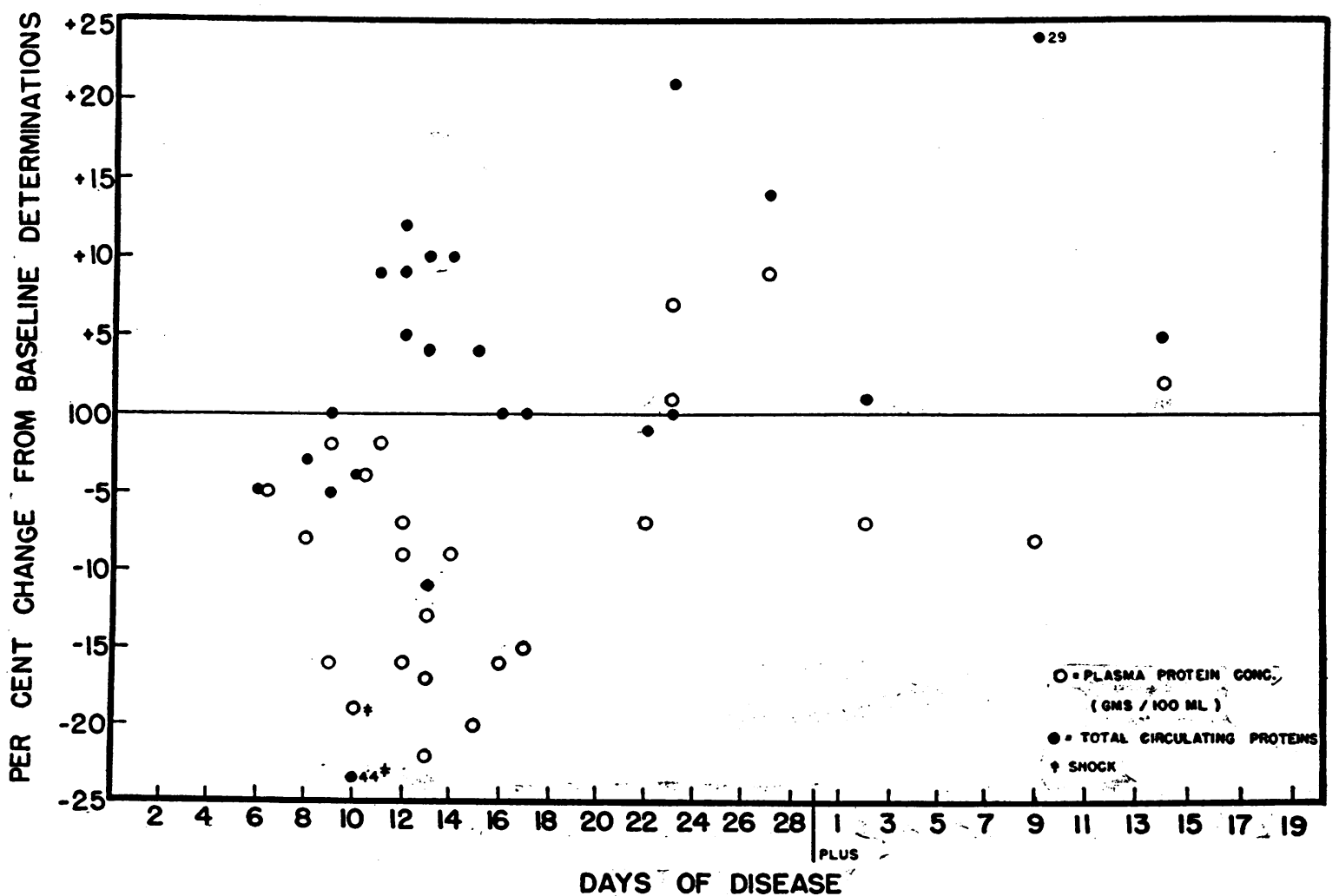

Fig. 9. Relation of Changes in Total Circulating Protein to Changes in Protein Concentration (GRAMS PER $100 \mathrm{ML}$.) 
the picture is altered when the total amount of circulating proteins is calculated (Figure 9), for it then becomes apparent that instead of a fall, there is more often no change or even a slight increase. While plasma dilution accounts for some of the fall in the concentration of plasma proteins during malaria, it fails to explain the reported $(10,11)$ selective plasma albumin decrease. A study now in progress, which combines blood volume studies with electrophoretic analysis of the plasma, may serve to clarify the question of quantitative alterations in the plasma protein fractions. Other factors which may play a rôle in the protein alterations, and which still remain to be appraised critically, are nitrogen imbalance, hepatic dysfunction, and the effect of the increased metabolic activity which accompanies fever.

\section{Shock}

During the course of these studies, 1 patient was encountered (Figure 10; Table II, Patient 2) who presented findings of sufficient interest to warrant a detailed discussion. This patient, on the tenth day of a severe falciparum infection, suddenly developed clinical signs of shock, including a rapid, almost imperceptible pulse, hypotension, moist, cooling skin, and semiconsciousness. Blood volume and other studies were performed while he was still in shock and prior to the administration of any intravenous fluids or medication. Instead of the anticipated elevation of the venous hematocrit, which is usually associated with the hemoconcentration of shock, the hematocrit index in this patient was 30,32 per cent lower than the control value and 19 per cent less than the index obtained 2 days previously. The plasma protein concentration also fell. The plasma volume had fallen 46 per cent below the control value to $1628 \mathrm{ml}$., erythrocyte mass 71 per cent to $697 \mathrm{ml}$., and the total blood volume 57 per cent to $2325 \mathrm{ml}$. In other words, although there had been a drastic reduction in plasma volume, this was not indicated by the hematocrit because of marked and almost concomitant destruction of erythrocytes. The latter was reflected in the enormous increase in plasma bilirubin, which had first been noted 2 days before. It seems reasonable to assume that the anoxemia resulting from erythrocyte destruction initiated the chain of events which terminated in the plasma decrease and shock. The marked reduction in total proteins, of the same general degree as the plasma volume, may be partly explained by increased capillary leakage.

The patient responded promptly to infusions of $500 \mathrm{ml}$. of erythrocytes and $500 \mathrm{ml}$. of plasma. Although he also received intramuscularly administered atabrine dihydrochloride, this could not have altered the immediate picture. Three days later the total blood volume had returned to normal with increases of 100 per cent above the shock levels in both plasma and erythrocyte volumes. The hematocrit, as expected, was still low. In spite of the slight increase in the concentration of plasma proteins, the calculated total amount of protein had increased greatly to a level slightly larger than the control value.

We have not been able to confirm these data on other patients as this is the only instance in which we have encountered this relatively rare complication of therapeutic malaria. The techniques employed were those used throughout this study; normal values were obtained on a control patient on the same day. Since the error which has been stated to occur in the study of shock by the use of T-1824 is thought to be due to increased loss of dye from the vascular bed and thus is responsible for plasma volume values which are inordinately high (12), the significance of the low values obtained in our patient would not be diminished by this factor. The correlation between the biochemical and volume studies done during this shock state, the studies done on prior and subsequent days, the clinical findings, and the theoretical concepts lead us to accept the qualitative accuracy of the direction and degree of the above described alterations.

The therapeutic implications of this case are clear, for had treatment been directed toward the improvement of shock by plasma transfusions alone, the clinical state undoubtedly would have been worsened. Although it was necessary to bolster the blood volume, to have done so without including erythrocytes might have been disastrous in view of this patient's marked anemia. Since the destruction of erythrocytes is such an integral part of malarial infections, it should be emphasized that transfusions of whole blood or erythrocytes are vital in the treatment of the shock which is not 


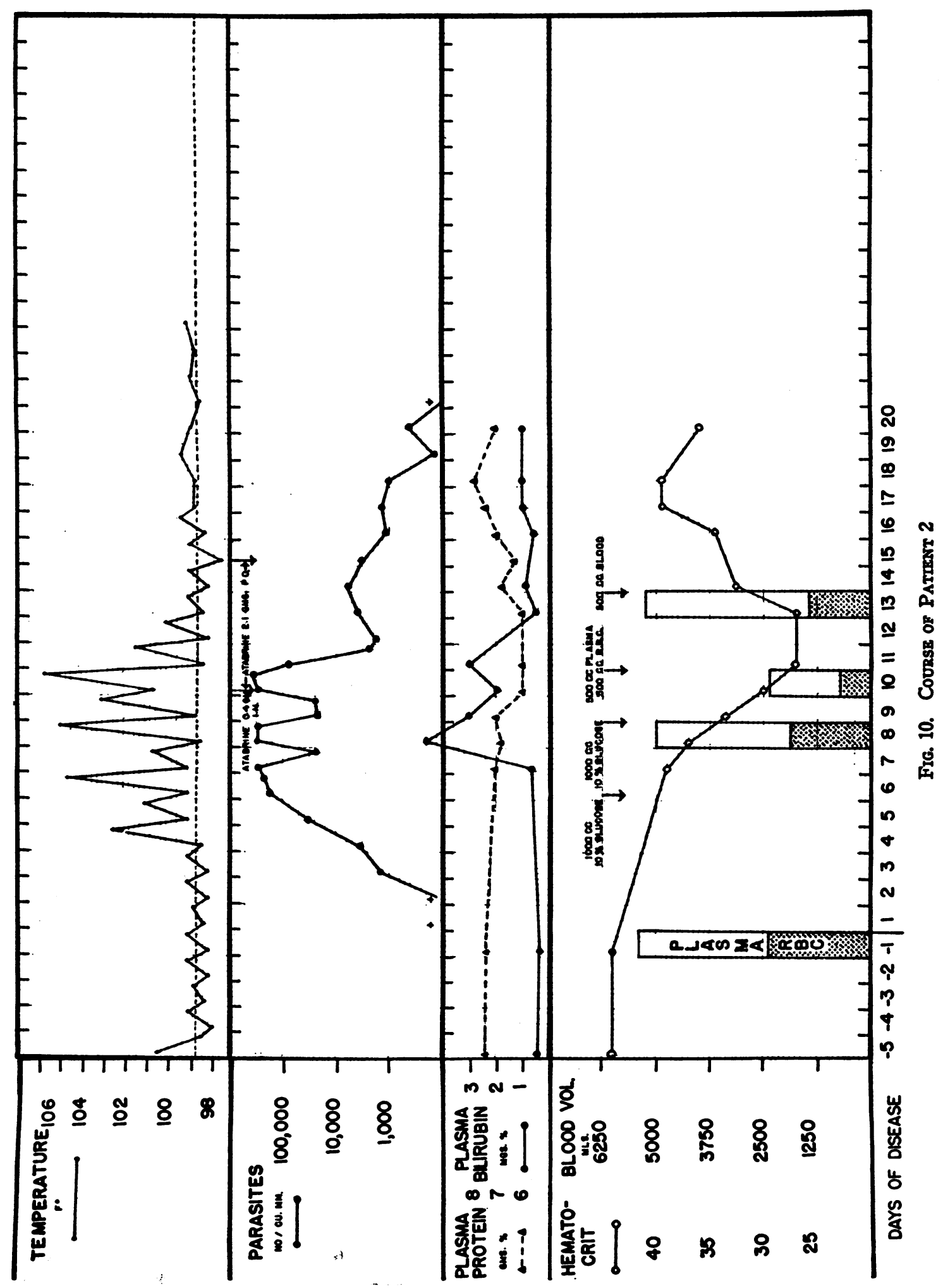


uncommonly encountered in neglected falciparum infections. Plasma infusions alone may reduce the ratio of circulating red cells below the critical level and result in a fatality.

\section{SUMMARY AND CONCLUSIONS}

1. The alterations in blood volume during the course of induced malaria in 9 patients have been studied by means of the dye T-1824.

2. (a) Plasma volume is almost uniformly increased during the active phase of vivax and falciparum infections. This increase reflects the ability of the body to maintain a fairly constant blood volume in the presence of erythrocyte destruction.

(b) The plasma volume increase may be disproportionately great following a paroxysm and thus the degree of anemia as measured by the hematocrit may be exaggerated.

(c) The plasma volume tends to be lower during the paroxysm than during the afebrile intervals.

3. The calculated mass of circulating erythrocytes progressively decreases with the course of vivax and falciparum infections.

4. (a) The calculated total blood volume tends to be slightly lower during the malaria paroxysm and higher during the afebrile intervals. These fluctuations are due mainly to alterations in the plasma volumes.

(b) The total blood volume tends to be reduced during convalescence.

5. The concentration, as well as total amount of plasma bilirubin, increases during the period of visible parasitemia and reflects erythrocyte destruction.

6. The normocytic anemia of clinically active malaria may be due to at least two factors; namely, erythrocyte destruction and hemodilution.

7. The concentration of plasma proteins falls during the clinical phase of vivax and falciparum infections. However, the total amount of circulating plasma proteins remains fairly constant and may in fact be increased.

8. (a) In one case of shock due to severe falciparum malaria, a drastic decrease in plasma volume and eyrthrocyte mass was observed. (b) These studies suggest that in the treatment of the shock which may be encountered in malarial infections, the administration of whole blood or erythrocytes is mandatory while plasma transfusions alone may be harmful.

It is a pleasure to acknowledge the constant advice and cooperation of Doctors Robert Briggs Watson, Henry Packer and William B. Wendel.

\section{BIBLIOGRAPHY}

1. Watson, R. B., The enumeration of malaria parasites. Bull. U. S. Army M. Dept., 1944, 81, 99.

2. Gibson, J. G., 2nd, and Evans, W. A., Jr., Clinical studies of the blood volume. I. Clinical application of a method employing the azo dye "Evans blue" and the spectrophotometer. J. Clin. Invest., 1937, 16, 301.

3. Hopper, J., Jr., Tabor, H., and Winkler, A. W., Simultaneous measurements of the blood volume in man and dog by means of Evans blue dye, T1824, and by means of carbon monoxide. I. Normal subjects. J. Clin. Invest., 1944, 23, 628.

4. Phillips, R. A., Van Slyke, D. D., Dole, V. P., Emerson, K., Jr., Hamilton, P. B., and Archibald, R. M., Copper sulfate method for measuring specific gravities of whole blood and plasma Bull. U. S. Army M. Dept., 1943, 71, 66.

5. Malloy, H. T., and Evelyn, K. A., The determination of bilirubin with the photoelectric colorimeter. J. Biol. Chem., 1937, 119, 481.

6. Rutstein, D. D., Thomson, K. J., Tolmach, D. M., Walker, W. H., and Floody, R. J., Plasma volume and "extravascular thiocyanate space" in pneumococcus pneumonia. J. Clin. Invest., 1945, 24, 11.

7. Hahn, P. F., Ross, J. F., Bale, W. F., Balfour, W. M., and Whipple, G. H., Red cell and plasma volumes (circulating and total) as determined by radio iron and by dye. J. Exper. Med., 1942, 75, 221.

8. Stead, E. A., Jr., and Ebert, R. V., Relationship of plasma volume and cell plasma ratio to total red cell volume. Am. J. Physiol., 1941, 132, 411.

9. Diggs, L. W., Personal communication..

10. Kopp, I., and Solomon, H. C., The relationship of hypoalbuminemia to the edema of malaria. Am. J. M. Sc., 1941, 202, 861.

11. Boyd, M. F., and Proske, H. O., Observations on the blood proteins during malaria infections. Am. J. Trop. Med., 1941, 21, 245.

12. Hopper, J., Jr., Winkler, A. W., and Elkinton, J. R., Simultaneous measurements of the blood volume in man and dog by means of Evans blue dye, T1824, and by means of carbon monoxide. II. Under abnormal conditions including secondary shock. J. Clin. Invest., 1944, 23, 636. 